\title{
DYNAMICS OF THE CONDITION OF GENESIAL HEALTH OF WOMEN WORKING ON CHEMICAL PRODUCTION
}

\author{
Ekatsiaryna Esis, Igor Naumov, Evgeniy Tishchenko, \\ Liudmila But-Gusaim, Aliaksandr Aleksandrovich
}

\author{
Grodno State Medical University
}

Esis E., Naumov I., Tishchenko E., But-Gusaim L., Aleksandrovich A. (2014), Dynamics of the condition of genesial health of women working on chemical production. Health Problems of Civilization, 4 (8), p. 9-15

\begin{abstract}
Summary: In modern social and economic conditions the condition of genesial health (further - GH) the female population remains to one of the most acute medico-social problems, being a national security prominent aspect. Research objective: scientifically to justify a complex of the preventive actions referred on optimization of medico sanitary maintenance of women working on chemical synthesis. Materials and methods: work is based on the systemic approach to a studied problem. Following methods are applied: sanitary-and-hygienic and sanitary-statistical. Effect of factors of industrial medium were evaluated on value of hygienic parameters in premises of shops of Open Society «Grodno Nitrogen» in a place of work of the patients, received at realization of gauging at the next certification of jobs for working conditions. For an estimation of condition GH of working women of chemical synthesis results of periodic medical examination and a condition of a case rate with time disablement (further - TD) during 2008-2012 are studied. At studying of a condition of genesial health of women working on Open Society «Grodno Nitrogen» it is established, that their professional work in the conditions of effect of harmful production factors of the chemical, physical and psycho physiological nature is accompanied by its aggravation that is shown by growth of a gynecologic and extra genital case rate, and also an obstetric pathology including with temporary disablement. For prophylaxis of disturbances GH of the yielded contingent of working women introduction of a complex of sanitary-and-hygienic, socially-hygienic, treatment-prophylactic actions is necessary.
\end{abstract}

Keywords: genesial health, women, chemical production

\section{Introduction}

In modern social and economic conditions the condition of genesial health (further - GH) the female population remains to one of the most acute medico-social problems, being a national security prominent aspect. On it in the National program of demographic safety, the attention is especially paid to 2011-2015 which is realized in the country now.

Experience of the previous researches in the given area testifies, that female GH is mortgaged from first days of a life and formed in the conditions of effect of factors of medico-social medium among which conditions of labour activity have special value (Chan et al. 2004).

In modern conditions of one of groups of increased "risk" on aggravation GH are the women of fertility age, working in the conditions of single-step effect of a different sort of the chemical toxins which effect can be shown both in the form of a synergy are, for example, potentiating, and in other qualitatively new effects not studied till now capable not only to lead to development of professionally caused obstetric-gynecologic pathology in the form of disturbances of specific functions of a female organism, but also to render teratogenic and embryo toxic action.

Thus, medico-social aspects GH of women-working women of chemical synthesis acquire strategic value, and the new methodological base of its formation and protection in the conditions of effect of harmful production factors is the important scientifically practical problem (Sorokin 2007). Thus at the present stage developments of a medical science to database creation, in particular, in system alarm, intermediate and end results in the field of an estimation of potential GH of the women who are carrying out industrial activity in the conditions of modern chemical production, special significance as the obtained data should become a basis for creation and introduction of technologies of prophylaxis should be attached (Escriba-Aguir et al. 2001). All noted above indicates an urgency of a problem and justifies scientifically practical interest to it.

\footnotetext{
Adress for correspondence: Igor Naumov, The Grodno State Medical University, Maksyma Gorkiego 80, 230015, Grodno, Belarus e-mail: kge_grgmu@mail.ru, phone: +375 (152) 43-54-51

Tables: 2 Figures: 3 References: 13 Full-text PDF www.hpc.edu.pl Copyright (c) Pope John Paul II State School of Higher Education in Biała Podlaska, Sidorska 95/97, 21-500 Biała Podlaska Indexation: Index Copernicus, Database AGRO, ProQuest, Polish Ministry of Science and Higher Education. This is an open-access article distributed under the terms of the Creative Common Attribution Non-commercial license (http://creativecommons.org/licenses/by-nc/3.0), which permits use, distribution and reproduction in any medium, provided the original works is properly cited, the use is non-commercial and is otherwise in compliance with the license.
} 
Research objective: scientifically to justify a complex of the preventive actions referred on optimization of medico sanitary maintenance of women working on chemical synthesis.

\section{Materials and methods}

Work is based on the systemic approach to a studied problem. Following methods are applied: sanitary-andhygienic and sanitary-statistical.

Work is executed on the largest petrochemical complex of the country of Open Society «Grodno Nitrogen» which includes more than 10 productions of chemical synthesis manufacturing to 40 names of production. At the enterprise work more than 10 thousand workers, from among working women constitute more than $30 \%$.

Effect of factors of industrial medium were evaluated on value of hygienic parameters in premises of shops of Open Society «Grodno Nitrogen» in a place of work of the patients, received at realization of gauging at the next certification of jobs for working conditions.

The condition of genesial health of 224 women working of Open Society «Grodno Nitrogen» at the age of 2045 years (the basic group) is studied. Among surveyed persons with the experience till 10 years have constituted $24,2 \%$, from 11 till 20 years - 42,8 \% and with a length of service more than 20 years - 33,0 \%. The control - 212 women at the age of 22-44 years living in of Grodno, but on a sort of professional work not contacting to toxic substances (working women of administrative and managerial service, housing and communal services, public health services other). The length of service of patients of control group has constituted: till 10 years - 36,8 \%, from 11 till 20 years - $38,8 \%$, over 20 years - $24,4 \%$.

For an estimation of condition GH of working women of chemical synthesis results of periodic medical examination and a condition of a case rate with time disablement (further - TD) during 2008-2012 are studied.

For an estimation of a current of pregnancy and labors the retrospective analysis of histories of labors (the registration form 096y) and histories of development of the newborn (the registration form 097y) at working women of chemical synthesis and the women of the control group who have received medical care in establishment of public health services «Urban hospital of the first help of of Grodno» for 2008-2012 is carried out.

The data processing, received as a result of research, lead with application of methods of variation statistics.

Degree of professional conditionality of disturbances of genesial health of working women carried out on the basis of account of relative risk (RR) and its etiological fraction (EF).

Research base have generated in electronic form, statistical accounts and charts have executed by means of computer programs Microsoft Excel, STATISTICA 6.0 (Borovikov 2008).

\section{Results}

It is established, that modern production of chemical synthesis is characterized by the big range of received production, a continuity of technological process, use of the modern process equipment.

Major of products of chemical synthesis are: caprolactam, a methanol, carbamidum, ammonia, a formic aldehyde, sulfuric acid, ethylene, propylene, benzene, ethyl benzene, toluene, styrene, butylenes, oxide ethylene, organic alcohols, heptyl etc.

Women in modern productions of chemical synthesis work in shops - machin-minders and operators, in laboratories - engineers-chemists, laboratory assistants of the chemical analysis.

Main element of activity of operators and machin-minders is observation over a course of technological process with resetting of parameters of its regimen from premises operational, record of parameters of a technological regimen in journals ( $45 \%$ of time of change), and also the control of a condition of the equipment possessed on the outside equipments ( $55 \%$ of time of change).

Laboratory assistants of the chemical analysis carry out researches of quality of raw materials, intermediate and definitive products of productions of organic synthesis with application of the modern analytical equipment. Laboratory assistants execute the large part of chemical analyses in fuming boards, thus to $60 \%$ of time of change are in position standing. Engineers-chemists supervise over realization of laboratory analyses, perform experimental and research works. Carry out necessary accounts under the lead analyses, tests and researches, analyze the received results and systematize them.

By results of the lead hygienic researches it is established, that the basic harmful factor of a working environment in the studied productions is the chemical, 1-4 classes of danger presented by toxic substances.

It is necessary to notice, that in the basic productions where there are chemicals of 1-2 classes of danger, irrespective of their concentration (at level or below marginal concentration), work of women is forbidden. However, in laboratories of the working woman are exposed to contact to these substances, carrying out analyses of quality used in chemical synthesis of substances, and also manufactured production. 
Principal cause of entering of harmful substances in air of a working zone of laboratories is necessity of fulfillment of separate analytical researches out of draught cupboards. Certain value in air pollution of a working zone takes place entering of harmful substances with affluent air. In premises of the laboratories placed in the basic productions, diffusive pollution by toxic products of the yielded production of air takes place.

The most widespread substances of 2-4 classes the dangers that are present at a production line of productions of chemical synthesis are presented in table 1. It is necessary to notice also, that According to Sanitary Rules and Norms 2.2.555-96, P.2.2.2006-05 number of chemicals to which working women contact, display also genesial toxicity (acetone, benzine, benzol, dimethylbenzene, dichloromethane, methyl benzene, a formic aldehyde, chloromethane, hloreten, oxide of ethylene, etc.).

By hygienic researches it is positioned, that concentration of harmful chemicals in the studied productions was up to standard or lower marginal concentration. However, coefficient of summation (further $-\mathrm{C}_{\text {sum }}$ ) substances of unidirectional action for engineers-chemists, laboratory assistants and hallmarks selectors constituted from 1,1 to 1,6 , and for operators, machin-minders of the cores and non-productive departments - from 0,7 to 1,9 .

On a volumetric factor with allowance for work of operators and machin-minders, engineers-chemists, laboratory assistants modern productions of organic synthesis belongs to the class of its genesial toxicity 3.1. Considering, that $\mathrm{C}_{\text {sum }}$ chemicals in shop steam - and water supply has constituted 0,7 and according to the Management of the P.2.2.2006-05 «Hygienic estimation of factors of an actuation medium and work flow. Criteria and classification of working conditions» working conditions have been carried to admissible ( 2 class), that allows to conclude about preferable use of work of women in these shops of productions of chemical synthesis.

The significant had effect of physical factors on a state of health of working women.

It is positioned, that hum in the basic workrooms, on the outside equipments, in premises pump nonproductive departments was to constants broadband.

Noise levels in the basic work rooms during all labour shift exceeded marginal levels: equivalent level of a sound has constituted 85-95 dBA and exceeded marginal level (further - EML) on 5-15 dBA, that corresponds to a class 3.2, that is harmful working conditions. In premises of laboratories equivalent level of a sound has constituted 85-90 dBA and exceeded EML on 5-10 dBA, that corresponds to a class 3.1.

Process equipment service was manufactured by women in the forced pose. So, during $80 \%$ of a labour shift the body of women machin-minders of gas separation, gas dewatering was in the inclined position with a deviation from a vertical, exceeding 30 degrees. At typists compressor, pump and refrigerator sets of shop of production of methanol in view of necessity of constant detour of the process equipment routine moving for change have constituted from $5,5 \mathrm{~km}$ to $10,3 \mathrm{~km}$.

Working conditions of operators, machin-minders of non-productive departments, engineers-chemists, laboratory assistants of chemical analysis laboratory-analytical management of modern productions of chemical synthesis have been carried to a class 3.1, that is to harmful working conditions.

For an establishment of a relationship of cause and effect of influence of working conditions on condition GH the analysis of structure and level of a gynecologic pathology at the women who were carrying out industrial activity in the conditions of influence of chemical toxins has been carried out.

By results of data of gynecologic and ultrasonic survey level of a gynecologic case rate on 100 women has constituted: 54,8 - in a basic group, 44,6 - in control group.

On one patient from a basic group 2,2 gynecologic diseases were necessary (the control - 1,8).

The most significant diseases at women working of chemical synthesis were disturbances of menstrual function, their frequency has constituted 27,2 $\pm 1,8$ (the control - 6,3 $\pm 1,8, p<0,05 ; R R=4,3, E F=76,7 \%$ ).

At studying of menstrual function it is positioned, that at patients of a basic group the age menarche has constituted 13,2 years (the control - 13,9).

In structure of disturbances of a menstrual cycle the first rating place was occupied with irregular character of a menses $(38,51 \pm 3,14 \%)$. The nosological form second for frequency was algodismenorrhea - $30,82 \pm 2,46 \%$. The third rating place was occupied with a hyperpolymenorrhea which share has constituted $12,26 \pm 2,18 \%$ (figure 1). 


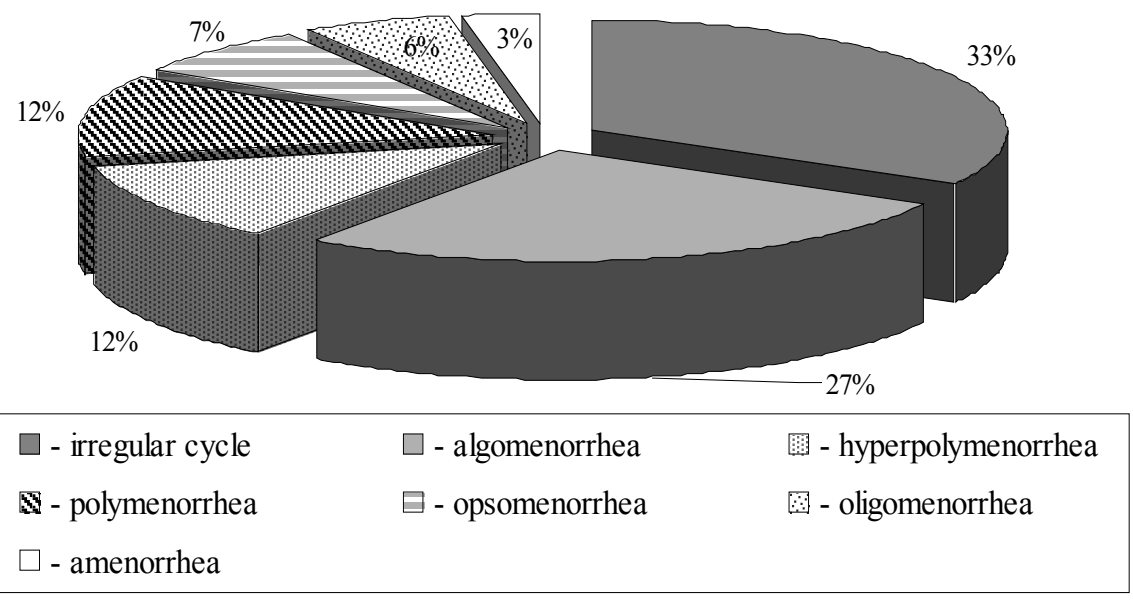

Figure 1. Structure of disturbances of a menstrual cycle at women working of chemical synthesis

High levels of menstrual disorders in workers identified in our investigation confirm the results of T. Wang et al. (2006) studies, where it was found that a violation of reproductive health in women of childbearing age by prolonged exposure to harmful chemical agents in concentrations not exceeding the maximum permissible values may occur without the presence of any clinical signs of poisoning.

The analysis of a current of pregnancy at working women of chemical synthesis has shown high frequency of an obstetric pathology in comparison with control group - 88,8 and 72,4 on 100 pregnant women, accordingly.

Frequency of pathology of pregnancy at working women of the basic and control groups (on 100 pregnant women) is presented in table 1.

Table 1. Frequency of a pathology of pregnancy at working women of the basic and control group, on 100 pregnant women

\begin{tabular}{|l|c|c|}
\hline \multicolumn{1}{|c|}{ Pathology kinds } & Basic group & Control group \\
\hline In total complicated pregnancy & $88,8 \pm 1,4^{*}$ & $72,4 \pm 0,9$ \\
\hline Iron deficiency anaemia & $73,2 \pm 1,9^{*}$ & $42,5 \pm 1,4$ \\
\hline Gestosis of II half of pregnancy & $52,3 \pm 2,4^{*}$ & $31,2 \pm 1,8$ \\
\hline Abortion threat & $44,2 \pm 2,4^{*}$ & $21,1 \pm 1,7$ \\
\hline Premature birth & $6,4 \pm 0,9$ & $2,4 \pm 0,7$ \\
\hline
\end{tabular}

The note: * an index of reliability concerning the control, $\mathrm{p}<0,05$.

It is positioned, that authentically more often pregnancy at working women of a basic group unlike control group became complicated an anemia of pregnant women - 73,6 $\pm 1,9(\mathrm{RR}=1,6, \mathrm{EF}=37,5 \%)$, gestosis of II half of pregnancy - 52,3 $\pm 2,4(\mathrm{RR}=1,9, \mathrm{EF}=47,4 \%)$, abortion threat - 44,2 $\pm 2,4(\mathrm{RR}=1,6, \mathrm{EF}=37,5 \%)$, premature birth $6,4 \pm 0,9(\mathrm{RR}=2,3, \mathrm{EF}=56,5 \%)$.

As is known, health of newborns is defined by the determined set of the factors attacking a pre-natal fetation, as from a maternal organism, and actuation medium factors (Sivochalova 2000). In this connection, by us have been studied perinatal outcomes at women-working women of chemical synthesis.

It is positioned, that authentic differences in delivery times in compared groups it has not been taped $(p>0,05)$ : the centre delivery time in a basic group has constituted 266,4 days, in control - 272,6 days. However frequency of occurrence of premature birth in a basic group has constituted - 6,4 $\pm 0,9 \%$ (the control - 2,4 \%, $p<0,05, R R=1,7$, $\mathrm{EF}=41,2 \%)$.

Statistically significant differences in ways of a delivery of women in compared groups are taped. So, among patients of a basic group operation cesarean sections has been executed to $34,8 \pm 2,9 \%$ (the control - $26,8 \pm 1,9 \%, p<0,05$ ).

The basic indications to an operative delivery were: anomalies of patrimonial activity $(28,8 \pm 2,7 \%$ and $8,4 \pm 0,9$ $\%$, accordingly; $\mathrm{p}<0,05)$; a pelvic presentation $(18,8 \pm 1,8 \%$ and $16,4 \pm 1,7 \%)$; an accompanying extra genital pathology $(18,8 \pm 1,8 \%$ and $14,2 \pm 1,5 \%)$; cicatrix on a uterus $(16,4 \pm 1,6 \%$ and $18,2 \pm 1,9 \%)$; premature amotio of normally located placenta $(8,2 \pm 0,9 \%$ and $4,8 \pm 0,4 \%$; $<<0,05)$.

Centre weight of fetuses at patients of both groups authentically did not differ and has constituted $3242 \pm 126,8$ gr. and $3428 \pm 119,4$ gr., accordingly. 
At primary survey of newborn both groups the condition of large majority of children $(85,4 \pm 4,2 \%$ - in a basic group and $95,6 \pm 4,9 \%$ - in control group) has been estimated as satisfactory with an estimation on scale Apgar of $8 / 9$ points. However $15,3 \pm 1,1 \%$ of babies of a basic group and $5,3 \pm 0,8 \%$ - from control group were born in a moderate severity level condition that has been caused by presence of neurologic symptomatology in the form of a syndrome of moderate oppression of the central nervous system and a syndrome of the raised nervouslyreflex excitability $(8,6 \pm 0,8 \%$ and $3,2 \pm 0,4 \%$, accordingly; $\mathrm{p}<0,05, \mathrm{RR}=5,2, \mathrm{EF}=80,8 \%)$, and also a syndrome of respiratory disorders $(6,8 \pm 0,7 \%$ and $2,8 \pm 0,4 \% ; \mathrm{p}<0,05, \mathrm{RR}=2,8, \mathrm{EF}=64,3 \%)$. Cases of a serious asphyxia in analyzed groups was not.

We studied the dynamics of congenital anomalies (malformations), deformations and chromosomal abnormalities morbidity in children due to the fact that a number of chemical toxins generated during the production cycle of Open Society «Grodno Nitrogen» are assigned to Class 1A (development toxicant) (Joffe et al. 2003).

At profound medical examination at children born by women-working women of chemical synthesis, authentically more often, than at newborns from mothers from a basic group congenital developmental anomalies of a foetus $6,9 \pm 1,4$ (the control $-2,3 \pm 0,4$ on 100 newborns, $p<0,05$ have been registered a different sort; $R R=3,0, E F=66,6 \%$ ).

By us it is positioned, that professional work in the conditions of influence of harmful factors result ins to disturbances of a state of health of the women-working women, displayed in TD.

So, at the analysis of a case rate with TD women-working women of chemical synthesis it is positioned, that case rate level on number of cases TD on 100 working from 2008 for 2012 was in limits 78,68 $\pm 2,35$ cases. Case rate level on number of days TD on 100 workers has constituted 722,97 $\pm 16,06$ day.

Case rate indexes on number of cases TD on 100 working for 2008-2012 in dynamics reached a maximum in 2009 and have constituted 84,8 cases, gradually dropping to 73,44 cases in 2012 Thus the case rate on number of days TD on 100 working also had the maximum value in 2009, constituting 769,4 days, the minimum value of an index has been registered in 2010 - 700,91 days.

At the analysis of a case rate with TD the groups of the diseases causing the most frequent labour losses on yielded production have been taped.

So, from 2008 for 2012 the greatest amount of cases of invalidity was necessary on diseases of organs of breath, disease of osteomuscular system, disease of system of a circulation of blood and digestion organs.

We studied the comparative dynamics of uterine leiomyoma morbidity, considering that a number of chemical toxins affect the metabolism of sexual steroid hormones or stimulate their effects on target organs, which is a possible cause of tumor development of certain locations (Sukumar et al. 2002).

In 2008-2012 significant growth of a case rate with TD, caused by growths of female genesial system is registered: the number of cases of diseases was enlarged by 10,3\%, and number of days - on 23,9\% (figure 2).

In 2008-2012 growth of a case rate with TD, caused by nonspecific inflammatory diseases of female genitals also is registered. So, the number of cases was enlarged by $6,7 \%$ and has constituted 7,43 on 100 working women.

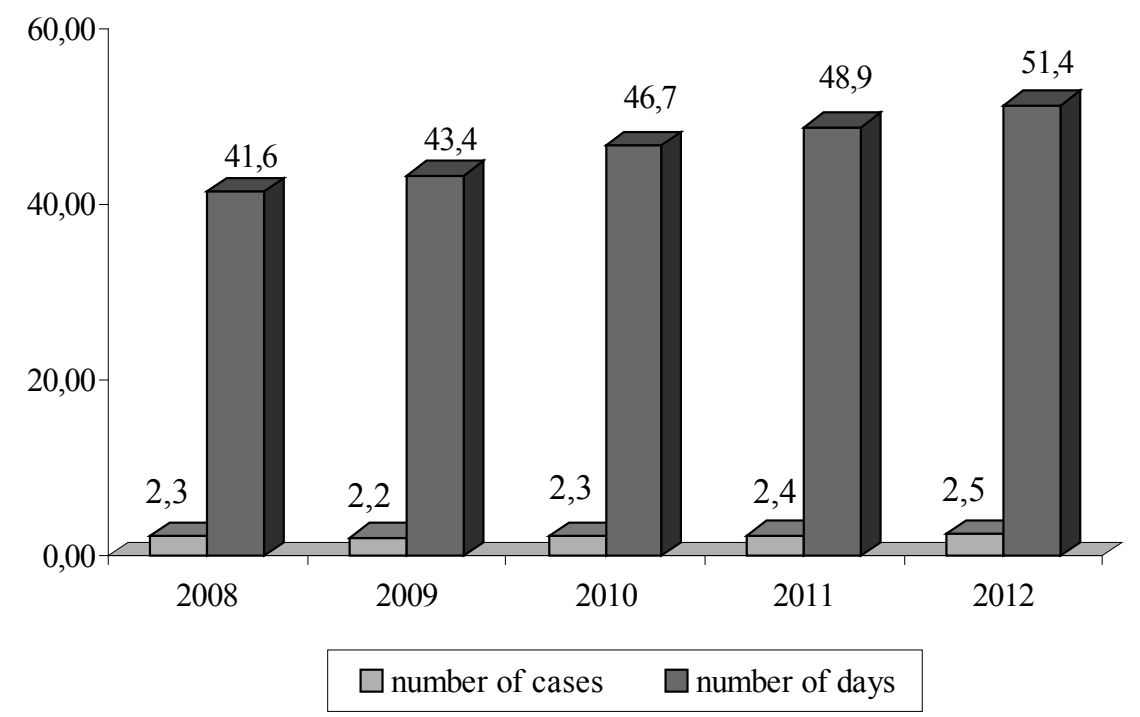

Figure 2. Dynamics of cases and days labour losses, caused neoplasms female genesial system 
In 2008-2012 we tap substantial growth of level of a case rate with TD, caused by complications of pregnancy and labors at women working of chemical synthesis. So, the number of cases TD on working women has increased on $6,6 \%$, and number of days TD - on $26,0 \%$ (figure 3 ).

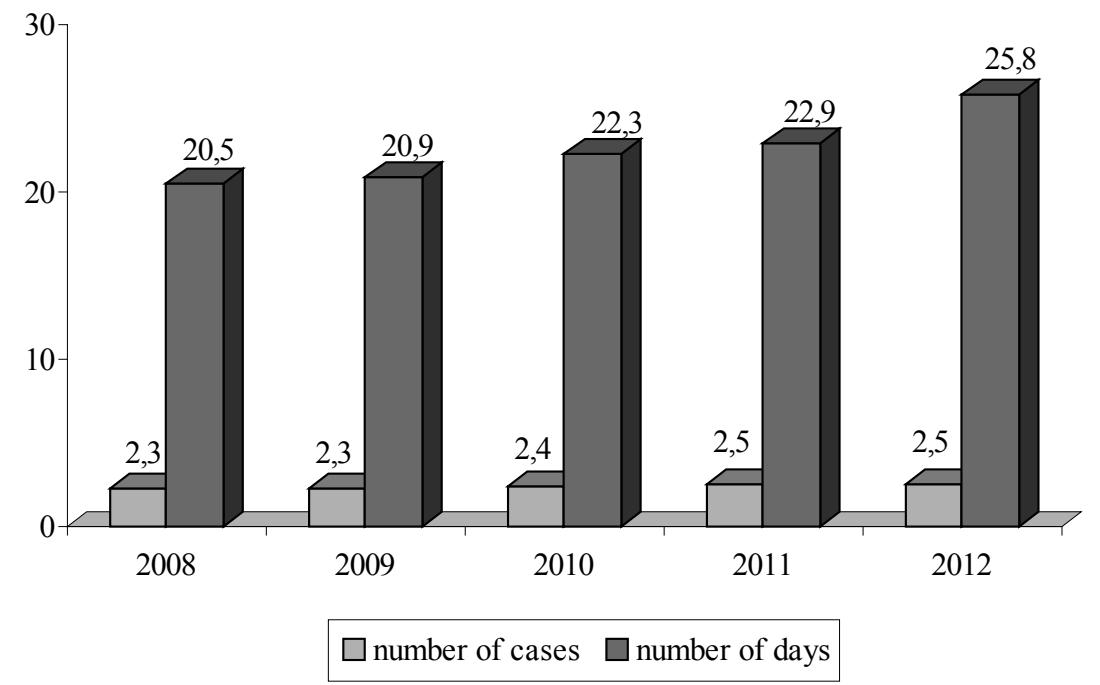

Figure 3. Dynamics of cases TD caused by complications of pregnancy and labors

Thus also the case rate with TD women-working women of the chemical synthesis, bound to growth of congenital anomalies at newborns was enlarged. So, if in 2008-2009 such cases were not registered, in 2010-2012

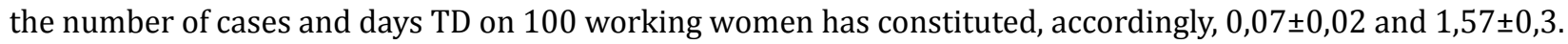

It is positioned, that the relative risk (RR) disturbances GH on the majority perinatal indexes at womenworking women of chemical synthesis has constituted more than 2,0 and its EF exceeded $50 \%$ that (table 2) testifies to high degree of professional conditionality and an essential role of working conditions in formation of disturbances of genesial health of the yielded category of patients.

Table 2. The estimation of relative risk and degree of professional conditionality of separate disturbances of genesial health

\begin{tabular}{|l|c|c|c|c|}
\hline \multirow{2}{*}{\multicolumn{2}{|c|}{ Perinatalnye indexes }} & \multicolumn{4}{c|}{ Estimation of degree of risk } \\
\cline { 2 - 5 } & rate, $\% \pm \mathrm{m}$ & $\mathrm{RR}$ & $\mathrm{EF}, \%$ & Conditionality degree \\
\hline Inflammatory diseases of a uterus and appendages & $46,1 \pm 2,2$ & 1,5 & 33,3 & the small \\
\hline Disturbances of a menstrual cycle & $27,2 \pm 1,8$ & 4,3 & 76,7 & very high \\
\hline Good-quality growths of a uterus & $18,6 \pm 1,6$ & 2,5 & 60,0 & the high \\
\hline Sterility & $9,1 \pm 1,2$ & 2,2 & 54,5 & the high \\
\hline Anemia of pregnant women & $73,6 \pm 1,9$ & 1,6 & 37,5 & the centre \\
\hline Gestoses II half of pregnancy & $52,3 \pm 2,4$ & 1,9 & 47,4 & the centre \\
\hline Abortion threat & $44,2 \pm 2,4$ & 1,6 & 37,5 & the centre \\
\hline $\begin{array}{l}\text { Syndrome of moderate oppression of the central } \\
\text { nervous system and syndrome of the raised } \\
\text { nervously-reflex excitability of newborns }\end{array}$ & $8,6 \pm 0,8$ & 5,2 & 80,8 & very high \\
\hline Congenital developmental anomalies & $6,9 \pm 1,4$ & 3,0 & 66,6 & \\
\hline Syndrome of respiratory disorders of newborns & $6,8 \pm 0,7$ & 2,8 & 64,3 & the high \\
\hline Premature birth & $6,4 \pm 0,9$ & 2,3 & 56,5 & the high \\
\hline
\end{tabular}

\section{Conclusions}

1. Professional work in the conditions of influence of harmful production factors result ins to disturbances of condition GH of working women and is accompanied by growth of a case rate with TD.

2. For prophylaxis of disturbances GH of the yielded contingent of working women introduction of a complex of sanitary-and-hygienic, socially-hygienic, treatment-prophylactic actions is necessary. 


\section{References:}

1. Borovikov V.P., Borovikov N.P. (1998), STATISTIKA ${ }^{\circledR}$. The statistical analysis and data processing in the environment of Windows ${ }^{\circledR}, 608 \mathrm{p}$.

2. Chan A., Keane R.J. (2004), Prevalence of induced abortion in reproductive lifetime. American Journal of Epidemiology, 5 (159): 475-480.

3. Escriba-Aguir V., Perez-Hoyos S., Saurel-Cubizolles M.J. (2001), Physical load and psychological demand at work during pregnancy and preterm birth. International Archives of Occupational Environmental Health, 74: 588-590.

4. Goldberg M.S., Parent M.E. (2001), Relation entre risquŭ de cancer du colon chez l'homme et exposition aux agents proffessionnels: Etude cas-temoins. Energ.-sante, 4 (12): 504-505.

5. Jojfe M., Bisanti L., Apostoli P. (2003), Time to pregnancy and occupational lead exposure. Occupational Environmental Medicine, 60 (60): 743-756.

6. Kissel J.C. (2005), Arsenic on the hands of children. Environmental Health Perspectives, 6 (113): $364-365$.

7. Kudaeva I.V., Masnavieva L.B. (2008), Influence of chemicals of the various nature on indexes of oxidizing stress. Med. work and industrial ecology, 1: 17-24.

8. Louekari K., Mroueh U.-M., Maidell-Munster L., Valkonen S., Tuomi T, Savolainen K. (2004), Reducing the risks of children living near the site of a former lead smeltery. Sci. Total Environ, 1-3 (319): 65-75.

9. Piatibrat A.O., Andrianov A.I., Panov P.B, Balahonov A.V. et al. (2009), Perfection of a treatment-and-prophylactic food for prophylaxis of occupational diseases and after treatment of the persons contacting to chemicals. The bull, 4: 65-72.

10. Sivochalova O.V. (2000), Reproductive health as a problem of medicine of work (concept). J. obst. and fem. diseases, 3(49): 63-67.

11. Sorokin G.A. (2007), Dynamics of a case rate with time disability as a professional risk index. Hygiene and Sanitation, 4: 43-46.

12. Sukumar Ch. et al. (2002), Apoptosis and necrosis in developing brain cells due to arsenic toxicity and protection with antioxidants. Toxicol. Lett, 1 (136): 65-76.

13. Wang T., Charette S., Smith M.I. (2006), An Unintended Consequence: Atal Amidarone Pulmonary Toxicity in a Older. Journal of the American Medical Directors Association 8 (7): 510-513.

Submitted: 06.06.2014

Accepted: 16.09 .2014 